\title{
ETNOGRAFIA E VIOLÊNCIA NO PAIIS DO APARTHEID: DOIS RELATOS SOBRE ÁFRICA DO SUL
}

\author{
Ethnography and violence in the country of apartheid: \\ two narratives about South Africa
}

\author{
Lorenzo Macagno*
}

\begin{abstract}
RESUMO
O artigo analisa duas narrativas sobre o apartheid da década de 1980. Um desses relatos engloba múltiplos microrrelatos: trata-se do trabalho do antropólogo norte-americano Vincent Crapanzano sobre os africâneres (ou bôeres) da África do Sul. Crapanzano realiza uma etnografia "plurivocal", "polifônica" e "dialógica". A outra narrativa é do jornalista sul-africano Rian Malan. Seu livro apresenta uma crônica das violências cotidianas decorrentes do apartheid. Quais são as estratégias estilísticas, políticas e éticas escolhidas no momento de descrever o apartheid? Quais são as consequências e os dramas morais produzidos por um sistema de segregação que não admitia ambiguidades classificatórias nem dissidências políticas ou étnicas? A partir de uma comparação dessas narrativas, este artigo indaga sobre os efeitos do apartheid na subjetividade individual e coletiva de uma sociedade dividida.
\end{abstract}

Palavras-chave: etnografia; violência; África do Sul.

\begin{abstract}
This article analyses two narratives about apartheid from the 1980s. One of these works contains multiple micro-narratives: it is the work of North American anthropologist Vincent Crapanzano on the Afrikaners (or Boers) of South Africa. Crapanzano carried out a "plurivocal", "polyphonic" and "dialogic" ethnography. The other narrative is by South African journalist Rian Malan. His book presents a chronicle of the violences that arose out of apartheid. What are the chosen stylistic,
\end{abstract}

* Professor Associado do Departamento de Antropologia - Universidade Federal do Paraná lorenzomacagno@hotmail.com 
political and ethical strategies when it comes to describing apartheid? What are the consequences and moral dramas produced by a system of segregation that does not admit classificatory ambiguities or political or ethnic dissidencies?Based on a comparison of these narratives, this article enquires about the effects of apartheid in the individual and collective subjectivity of a divided society.

Keywords: ethnography; violence; South Africa 
The generation of white South Africans to which I belong, and the next generation, and perhaps the generation after that too, will go bowed under the shame of the crimes that were committed in their name. Those among them who endeavour to salvage personal pride by pointedly refusing to bow before the judgment of the world suffer from a burning resentment, a bristling anger at being condemned without adequate hearing, that in psychic terms may turn out to be an equally heavy burden².

Em afrikans (ou africâner), uma língua creolizada derivada do holandês antigo, apartheid significa separação ou segregação. O termo foi utilizado a partir de 1948 na África do Sul para designar a política oficial de segregação implementada pelo governo até 1990. Ao longo desse período, a África do Sul foi o único país do mundo a definir os direitos constitucionais dos seus cidadãos segundo a cor da pele.

Da chegada dos holandeses à península do Cabo, em 1652, à instauração oficial do apartheid pelo Partido Nacional, os descendentes daqueles primeiros colonos foram construindo uma ideologia exclusivista que terminaria dando forma e consistência ao nacionalismo africâner. A Liga Africâner dos Irmãos (Afrikaner Broederbond), fundada em 1918, teve um papel fundamental na promoção e consolidação desse nacionalismo. A Liga, ou "irmandade", só aceitava entre os seus membros homens brancos de língua afrikans com um mínimo de 25 anos, protestantes, possuidores de "bom caráter" e que considerassem

\footnotetext{
2 “A geração de sul-africanos brancos à qual pertenço e a geração seguinte e, talvez, também a geração depois dessa, irá se curvar sob a vergonha dos crimes cometidos em seu nome. Aqueles entre eles que se empenham em conservar o seu orgulho pessoal, recusando-se terminantemente a se curvar diante do julgamento do mundo, sofrem de um ressentimento abrasador, de uma raiva mordaz ao serem condenados sem ser suficientemente ouvidos, o que, em termos psíquicos, pode acabar se transformando em um peso igualmente grande" [as traduções do inglês são da minha autoria].
} 
a África do Sul como sua terra mãe. O grupo promovia a exaltação de um povo/nação africâner (o Volk) com um ethos e singularidades específicas, sobretudo no que diz respeito à língua e cultura, e separável dos outros grupos "por ser essencialmente diferente". 3

Sobre os descendentes dessa "tribo branca" se debruçou o antropólogo norte-americano Vincent Crapanzano 4 , autor do livro, ainda não traduzido ao português, Waiting. The whites of South Africa (1986). Crapanzano começou a pensar nesse livro no início da década de 1980, quando era professor de antropologia na Universidade de Harvard. Nesse interim, um jovem sul-africano branco chega, na qualidade de pesquisador visitante, ao departamento de antropologia daquela universidade. Crapanzano, um "liberal" progressista que repudiava o apartheid, enxerga a seu novo colega com desconfiança. Porém, em pouco tempo a desconfiança inicial se transforma em um entusiasmado diálogo e, finalmente, em um estímulo para a realização de um trabalho de campo no país do apartheid. Poucos anos depois, os resultados dessa pesquisa assumiriam a forma de uma etnografia "experimental" sobre os africâneres da África do Sul. Crapanzano chega ao país em um momento decisivo. O regime do apartheid, apesar de algumas tímidas reformas que começavam a ser implementadas pelo presidente Pieter Willem Botha (1916-2006), encontrava-se, ainda, em pleno funcionamento.

3 DE JONGE, Klaas. África do Sul. Apartheid e resistência. São Paulo: Cortez Editora, 1991, p. 41-42.

4 Conheci Vincent Crapanzano em 2004, na ocasião da sua visita ao Brasil quando ministrou, em Caxambu, uma das conferencias do $28^{\circ}$ Encontro anual da ANPOCS (Associação Nacional de Pesquisa e Pós-Graduação em Ciências Sociais). Ao finalizar a palestra, a antropóloga Yvonne Maggie - anfitriã do visitante - convidou-me (eu estava sentado na parte detrás do auditório) para que me aproximara a conversar com ele. Já conhecia seu livro, "Waiting..." e, em algum momento da breve conversa perguntei-lhe sobre seu trabalho de campo na África do Sul. Crapanzano considerava que a realização dessa pesquisa - e o livro - era uma necessidade imperiosa em aquele momento político, de mudanças e novos desafios para a África do Sul. 
Evoquemos, brevemente, as coordenadas das forças políticas da década de 1980, período político em que Crapanzano realiza sua pesquisa de campo. Do lado esquerdo desse espectro, uma das grandes vertentes se identificada com Consciência Negra (Black Consciousness), grupo fundado por Steve Biko, assassinado em 1977. Tratava-se de um movimento no qual não podiam militar brancos. Lembremos que, em 1986, os principais líderes do movimento Consciência Negra convocam em Johanesburgo a imprensa afim de denunciar membros da, supostamente não violenta, Frente Democrática Unida (UDF) que contava, entre suas fileiras, ao bispo Desmond Tutu. A UDF erá, também, próxima ao Congresso Nacional Africano, fundado por Nelson Mandela. Nesse ano, os enfrentamentos entre os seguidores do Congresso Nacional Africano, de Mandela, e os seguidores de Consciência Negra tinham se tornado muito violentos. Havia interior de Consciência Negra uma ala mais radical: a AZAPO(Azanian People’s Organization), organização do "povo azaniano". Consciência Negra "...criou uma bandeira para o país livre que dela resultaria e até lhe deu um nome: Azania, o antigo termo árabe para a terra incógnita que ficava ao sul de Zanzibar. Azania seria uma república popular "negro comunalista", livre da praga do "capitalismo racial". ${ }^{5}$ Para a AZAPO, o inimigo dos negros era o branco (seja de origem britânica ou africâner). O movimento proclamava que o objetivo da luta devia ser a "redenção da terra", livre da presença dos "conquistadores brancos". A oposição ao apartheid se construía, portanto, com duas frentes: uma mais moderada (o Congresso Nacional Africano de Mandela) e uma mais radical (Consciência Negra e os seguidores de Biko).

Do lado direito e branco do espectro político havia duas grandes vertentes. A vertente politicamente mais extrema era configurada pelo Movimento de resistência Africâner, apoiado por uma

MALAN, Rian. Coração Traidor: O dramático reencontro de um jornalista sul-africano com seu país e sua consciência. São Paulo: Editora Best Seller, 1989, p. 306. 
série de seitas paramilitares de cunho fascista. A mais moderada era o Partido Nacional Africâner (PNA) que, na altura, estava no governo sob a presidência de P. W. Botha. Devido, sobretudo, às pressões internacionais,o PNA, apoiado pela maioria dos brancos, trilhou o caminho da "reforma gradual". Seus militantes, além da própria figura de P. W. Botha, admiravam Ronald Reagan e Margaret Tatcher. O PNA acabou realizando uma série de concessões: revogou a proibição do casamento inter-racial e ofereceu liberdade aos prisioneiros políticos que estivessem dispostos a renunciar à violência. Essas medidas integravam a chamada "transição". Contudo, o poder continuaria sendo monopólio dos brancos. É, portanto, nesse contexto de forças e tensões políticas que Crapanzano se instala na África do Sul para desenvolver sua etnografia.

$\mathrm{Na}$ sua estrutura, diz Crapanzano, “...Waiting me resultou parecer como um romance; romances, tal como o crítico literário russo Mikhail Bakhtin observou, são em essência, plurivocais". ${ }^{6}$ A etnografia plurivocal de Crapanzano pretende colocar em segundo plano a presença do autor e, na sequência, dar lugar às vozes dos seus entrevistados. O questionamento da "autoridade" etnográfica tem sido um assunto longamente discutido na denominada antropologia pós-moderna. ${ }^{7}$ Por ora, cabe interrogar: quais são os limites das abdicações autorais no contexto de um sistema, o apartheid, baseado

6 CRAPANZANO, Vincent. Waiting: The Whites of South Africa. New York: Vintage Books, 1986, p. XIII.

7 Estas preocupações foram abordadas no conhecido conjunto de ensaios publicados por Clifford e Marcus, cf. CLIFFORD, James \& MARCUS, James. 1986. Writing Culture. Berkeley: University of Chicago Press, 1986. Um comentário crítico sobre as etnografias "experimentais" em antropologia pode ser encontrado em: SANGREN, P. Steven. Rhetoric and the Authority of Ethnography. 'Postmodernism' and the Social Reproduction of Texts. Current Anthropology, vol. 29, no 3, p. 405-435, 1988. Também nos seguintes artigos: SPENCER, Jonathan. Anthropology as a kind of writing. Man, vol. 24, $\mathrm{n}^{\circ}$ 1, p. 145-164, 1989; FABIAN, Johannes. Presence and Representation: The Other and Anthropological Writing. Critical Inquiry, vol. 16, nº 4, p. 753-772, 1990. 
no terror e a violência? Ou, para dizê-lo de uma outra forma, quais os limites do relativismo antropológico e das abstenções do juízo em relação a um regime que não admitia ambiguidade? Em grande medida, Crapanzano é prisioneiro de um duplo vínculo moral. Mariza Peirano, uma das poucas antropólogas no Brasil que se deteve na análise do trabalho de Crapanzano, explicita esse dilema de maneira mais enfática: conscientemente ou não "...ele enfrenta, assim, o desafio de conciliar a ideologia do meio intelectual (ocidental ou norte-americano) que condena o apartheid como uma das formas mais cruéis de discriminação social e a ideologia relativizadora da antropologia". ${ }^{8}$ Esse dilema alimenta um ponto de partida polêmico, que Crapanzano busca sublinhar em seu livro: dominantes e dominados são, igualmente, vítimas de um sistema que os supera e os condiciona.

Una etnografia experimental

Waiting is about the effects of domination on everyday life - not the everyday life of people who suffer domination but of people who dominate...it is about the discourse of people who are privileged by that power and, paradoxically, in their privilege victims of it $^{9}$.

Vincent Crapanzano, Waiting. The Whites of South Africa, 1986, p. XIII

Em grande medida, a etnografia plurivocal de Crapanzano permitirá dar voz ao "homem médio" africâner (vulgarmente co-

8 PEIRANO, Mariza G. S. O encontro etnográfico e o diálogo teórico. In: Peirano, M. Uma Antropologia No Plural. Três experiências Contemporâneas. Brasília: Editora Universidade de Brasília, 1991, p. 131.

9 "Waiting se refere aos efeitos da dominação na vida cotidiana - não da vida cotidiana de quem sofre a dominação, mas daqueles que exercem a dominação (...) se refere ao discurso de pessoas que são favorecidas por esse poder e, paradoxalmente, no seu favorecimento, vítimas dele". 
nhecido como bôer ${ }^{10}$.). As narrativas apresentadas são uma amostra do senso comum da "tribo branca" africana cuja certeza recorrente é considerar o apartheid como a única saída viável e coerente para a África do Sul moderna. Mas, por sua vez, esse senso comum se constrói através do mito nacional e heroico: a narrativa de um povo escolhido por Deus e, ao mesmo tempo, oprimido pelos ingleses desde a guerra anglo/bôer.

A etnografia de Waiting coloca em evidência alguns marcos históricos aos quais os africâneres retornam constantemente para justificar sua posição subalterna em relação à presença britânica. Um desses marcos nasce com "The Great Trek", a grande marcha que, por volta de 1836, os bôeres (africâneres) empreenderam a partir da cidade do Cabo até o nordeste, para fundar Transvaal e o Estado Livre de Orange.

Outro desses grandes marcos fundadores da nacionalidade africâner está constituído pelas duas guerras anglo-bôer (em 1880 acontece a primeira e, entre 1899 e 1902, a segunda). A partir desse momento, o nacionalismo africâner terá de buscar subsídios no seu passado para legitimar a sua política de segregação. Ao mesmo tempo, terá de apelar a poderosos traços diacríticos a fim de se inventar como grupo. Um desses diacríticos será a língua:

...Em 1925, o africâner foi finalmente reconhecido como língua, e na década de sessenta, após África do Sul se tornar uma república, o Monumento à língua Africâner, uma imponente hipérbole de concreto e granito, foi construída sobre uma montanha com vista panorâmica a Paarl [na província de Western Cape] com o objetivo de comemorar a "grandeza" (...) do desenvolvimento

10 No século XVIII, o termo bôer significava um fazendeiro branco. No século XIX, o termo começou a ser empregado para se referir aos africâneres em geral. Quando é utilizado por anglofalantes (ou por brancos de origem britânica) para descrever aos africâneres, veicula uma conotação pejorativa, de atraso ou falta de "cultura". Ver, SAUNDERS, Christopher. Historical Dictionary of South Africa. London: The Scarecrow Press, 1983, p. 28. 
cultural e político Africâner. Esculpidas sobre o caminho que conduz ao monumento estão as palavras do primeiro ministro do Partido Nacional que foi um dos arquitetos do apartheid, Daniel Malan:..."Esta é a nossa verdade, nossa seriedade, nossa urgência" [em afrikans: dit is ons erns]. ${ }^{11}$

Segundo Crapanzano, aquele monumento significa a perda do poder político dos ingleses e o triunfo no nacionalismo africâner. A segunda guerra anglo-bôer, lembremos, emerge como um momento que explicita os mais fortes e irredutíveis enfrentamentos entre os dois grandes grupos de descendência europeia. No discurso dos interlocutores de Crapanzano, esses marcos convertem-se em estratégias retóricas para eludir uma importante questão: a relação com os negros sul-africanos. Ou seja, diante o etnógrafo norte-americano e "progressista", a estratégia do interlocutor africâner será a de se colocar no lugar da vítima do "imperialismo" inglês:

A guerra de outubro de 1899, que devia ter sido ganha no Natal (...), na verdade estendeu-se até junho de 1902. 22.000 dos 450.000 soldados imperiais e coloniais que lutaram na África do Sul encontraram suas sepulturas ali. Aproximadamente 400.000 cavalos, mulas e burros britânicos foram perdidos. Sete mil comandos Bôeres foram assassinados. Havia ali algo mais do que 87.000 deles. Mais de 28.000 mulheres e crianças bôeres morreram em campos de concentração Britânicos ${ }^{12}$.

Qual era, pois, a reação do "informante" africâner diante do questionamento do apartheid por parte das democracias ocidentais? Em geral, a reação era a mesma que recaía sobre os ingleses: a acusação de hipocrisia. Ou seja, os africâneres, diferentemente dos "hipócritas", aceitavam, sem mais, algo que já estava dado na "natureza": a diversidade humana como criação divina. "Estou contra o apartheid", dizia um africâner utilizando um jogo de palavras: "Quero dizer a

11 CRAPANZANO, Vincent. Waiting...op.cit. p. 34.

12 Ibid., p. 51 
palavra 'apartheid' [estou contra a palavra apartheid]...Essa palavra é a que criou os nossos problemas. Os ingleses pensam que quer dizer "apart-hate"("ódio-separado"). Na sequência, o interlocutor de Crapanzano apresenta sua justificativa:

O apartheid é algo natural. Significa "separação" (...) Não há necessidade de nomeá-la. Você tem apartheid nos Estados Unidos. Eles o têm na Europa. Você nunca convidaria a sua empregada doméstica para jantar. Você não se sentiria confortável, ela não se sentiria confortável. Vocês possuem vidas separadas. Isso é tudo o que o apartheid significa. Só que aqui na África do Sul temos que nomear todas as coisas. Esse é o nosso problema. Nós fornecemos a vocês o termo, e agora, com ele, vocês se sentem à vontade para nos criticar ${ }^{13}$.

Nessa justificativa anti-intelectualista - mas também religiosa - o apartheid está na "natureza das coisas", as diferenças estão "simplesmente ali". Portanto, não resta senão chamar as coisas pelo seu nome. Os ingleses e a opinião pública internacional seriam, aos olhos dos africâneres o suficientemente hipócritas por não quererem nomear o que também existe nos seus países.

Os germens daquele orgulho nacional encontravam, sobretudo, um repertório inesgotável na evocação auto-vitimizante da guerra anglo/bôer. "Falo às minhas crianças acerca da guerra", comenta o Dr. Jakobus Steyn a Crapanzano, "...Os levo a visitar os campos de concentração. Me sinto orgulhoso de lhes mostrar como o nosso povo sofreu [nas mãos dos britânicos]"14. A fonte no orgulho africâner não provém apenas da comunidade de memória que o sofrimento da guerra produziu. Outra fonte importante desse nacionalismo perene está no uso que os africâneres - educados, sobretudo, no julgo da Igreja Reformada Holandesa - fazem da própria Bíblia. Segundo essa narrativa, o princípio do desenvolvimento separado das nações

\footnotetext{
13 Ibid., p. 57.

14 Ibid., p. 53.
} 
contra o "pecado" da miscigenação é um mandato indeclinável, pois, conforme essa visão, é necessário manter intacta a criação e a sua diversidade: "O princípio do desenvolvimento separado tal como tem vindo a servir ao nosso próprio povo está em completo acordo com a Bíblia que ensina a unidade na diversidade..."15.

No dia-a-dia, Crapanzano percebe uma diferença na maneira pela qual ingleses e africâneres se auto-apresentavam. Era difícil para Crapanzano fazer com que os ingleses falassem sobre si próprios:“... Usualmente eles [os ingleses] interrompiam minha interpelação, apresentando a si mesmos como colegas informais, logo a seguir começavam a descrever os Africâneres". Diante da insistência do antropólogo em desviar da conversa, e fazer com que falassem de si próprios, os ingleses começavam a falar dos "coloured", dos zulus, dos xhosa, ou de qualquer outro grupo que possa captar o interesse do antropólogo, evitando, assim, a constrangedora situação de se auto-enxergarem como "objetos" da pesquisa ${ }^{16}$. Quando o objetivo era indagar sobre a noção de pessoa entre os ingleses, Crapanzano encontrava o caminho fechado. Essa noção parecia inescrutável. Acontecia algo muito diferente com os africâneres. Nestes, a consciência de comunidade os levava a falar de si com orgulho. Entre os africâneres, dirá Crapanzano, "A "pessoa" está incrustada, (...) de filiação nacional, racial e étnica, de participação partidária, de crença religiosa e de tradição cultural"17.

Ora, que lugar ocupavam os negros no discurso dos interlocutores de Crapanzano? Como vimos, os africâneres optavam muitas vezes pela estratégia retórica de aparecer como vítimas diante dos ingleses podendo, assim, eclipsar ou minimizar as suas próprias

15 Essas são as palavras de A. B. Dupreez, um dos pastores da Igreja Reformada Holandesa na África do Sul, por volta da década de 50; apud. Crapanzano, p. 100.

16 CRAPANZANO, Vincent. Waiting...op.cit. p. 26.

17 Ibid., p. 38. 
atitudes em relação aos negros: "Não acho que tenhamos feito aos negros as mesmas coisas que os ingleses nos fizeram", dizia Jakobus Steyn ${ }^{18}$. Por momentos, o discurso dos brancos (tanto dos africâneres como dos ingleses) evidenciava a indiferença em relação aos negros (ou aos coloureds, aos "asiáticos", aos "kaffirs" e assim por diante), como se o apartheid, existente no plano das relações sociais, tivesse, também, seu correlato no plano do simbólico. Contudo, o negro aparecia como um "problema" preocupante quando se tratava, sobretudo, daqueles que viviam em Soweto, o grande subúrbio de Johanesburgo. Nesse caso, a preocupação era acompanhada pela boa consciência civilizatória:

Gostemos ou não, Soweto é uma realidade, e nós precisamos dessa gente. Não podemos avançar sem o trabalho deles. Portanto, em algum ponto, eles têm que ter uma existência legal e têm que ser reconhecidos. Temos que fazer alguma coisa a respeito, já que as pessoas que nós tiramos de lá são capazes de fazer o que nós precisamos, o que nós queremos que eles façam. Precisamos treinar essas pessoas para que eles sejam mecânicos, eletricistas, técnicos ${ }^{19}$.

A "espera" ["Wainting"] dos africâneres (que justifica o título do livro) consiste em uma preocupação ambígua tanto em relação ao presente quanto ao futuro. Contudo, por ser o futuro sinônimo de "medo", o presente acaba assumindo uma intensidade desproporcional. É preciso, portanto, minimizar - ou simular - as ansiedades em relação ao futuro. Os desfechos da tensão entre africâneres e negros, por exemplo, situam-se no futuro e, portanto, encontram-se em um segundo plano no discurso dos interlocutores de Crapanzano. Entretanto, as ansiedades provenientes da tensão africâneres/ingleses localizam-se no presente e, sendo menos ameaçadoras, aparecem o tempo todo no discurso dos primeiros: silêncios, quando se trata de

18 Ibid., p. 51.

19 Ibid. p. 305. 
falar da tensão africâneres/negros e excesso de "ruídos", no caso da tensão africâneres/ingleses. Os silêncios manifestados pelos atores desta etnografia multivocal buscam, mesmo que inconscientemente, domesticar no plano do simbólico aquilo que resulta intolerável no plano do real.

A partir desse ponto a crítica e a interpelação à obra de Crapanzano parece mais ou menos previsível: será que, dentro desse sistema injusto, e no momento de distribuir responsabilidades, é legítimo concluir que todos - dominantes e dominados - são igualmente vítimas? Aqui, a "missão moral" parece ceder lugar à "missão intelectual", já que o sistema que oprime a todos não seria, nesse caso, o próprio apartheid, mas o sistema de classificações que esse sistema engendra e impõe. As categorias "branco", "negro", "coloured" supõem um sistema de nomeações. Essas classificações raciais e étnicas “...descrevem um ser essencial. Permitem estereótipos mecânicos e generalizações promíscuas; prescrevem um comportamento social e determinam uma perturbadora distância social", bem como "subministram as bases para uma compreensão do apartheid no seu estrito sentido jurídico"20.

A questão da linguagem é decisiva, como se o mero discurso criasse a própria realidade da dominação e lhe atribuísse um sentido. Aqui, o experimento etnográfico também tem a sua consequência política ou, como diz Peirano: "Ao decidir dar a palavra aos entrevistados, Crapanzano procurou recuperar a 'qualidade barroca' característica da realidade social, e que é tantas vezes sacrificada na descrição etnográfica quando o autor se mantém preso a um 'classicismo teoricamente inspirado'..."21. Mas odiscurso dos 'dominantes' (como qualquer outro discurso) nunca pode ser transparente. Consciente ou inconscientemente, ele sempre veicula um interesse; por

20 Ibid. p. 19.

21 PEIRANO, Mariza G. S. O encontro etnográfico e o diálogo teórico, op. cit. p. 133 
isso a importância da interpelação que introduz o escritor sul-africano J. M. Coetzee, evocado no ensaio de Peirano, eque Crapanzano parece minimizar: “...os informantes estavam conscientes de representarem a África do Sul para um livro destinado a uma audiência internacional"22. Essa expectativa de recepção por parte dos interlocutores de Crapanzano altera, pois, as condições de produção do saber antropológico. Mais uma vez, a multivocalidade bakhtiniana - apesar das boas intenções do "autor" - nem sempre opera como uma aliada insuspeita. Essa etnografia polifônica e multivocal, supostamente não autoritária (nem "autoral”), envolve, no seu imperativo relativista, um risco iminente: parte de uma comunidade de falantes ideais, na qual todos usufruem do mesmo poder discursivo e possuem o idêntico direito a serem ouvidos e compreendidos. Em uma refinada reflexão, pertinentemente intitulada "Diálogo", Crapanzano já manifestava os limites dessa quimera dialógica: "temos de lidar humildemente", dizia, "com as nossas limitações de percepção e interpretação"; e mais adiante reconhece "...As etnografias dialógicas representam diálogos. Podem criar a ilusão do imediato, mas, na verdade, estão sujeitas a todos os tipos de limitações inerentes à representação..."23.

No país do apartheid, as nomeações indentitárias, impostas através das leis de separação, têm, sem dúvida, uma eficácia poderosa. Crapanzano é consciente dessa imposição quando afirma que toda classificação essencialista tem uma característica: é estática. Nesse sistema "fechado", a tentativa de introduzir novas categorias é uma tarefa vã, já que o fundamento epistemológico - e político - que sustenta a segregação insiste na sua perenidade e continuidade. Aqui, o etnógrafo questiona os lugares comuns e as inoperâncias do discurso politicamente correto. "Quando isolamos o racismo", diz, "..., corremos o risco de perpetuar o status quo introduzindo uma categoria

22 J. M. Coetzee, apud. Peirano, ibid., p. 142.

${ }^{23}$ CRAPANZANO, Vincent. Diálogo. Anuário Antropológico, Brasília, no 88, p. 59-80, 1991; para as citações acima ver, respectivamente, p. 70 e p. 73. 
eufemística. Isso fica evidente na África do Sul, onde muitos brancos "esclarecidos" já não falam mais em termos de "raça", mas de "cultura", "etnicidade", "classe", "caráter", enquanto continuam fazendo as mesmas discriminações sociais. Também acontece nos Estados Unidos, onde para muitos o discurso "da cultura da pobreza", perpetuando termos racistas, aplicasse essencialmente aos negros e aos hispânicos"24. Como antropólogo que procura relativizar, Crapanzano se posiciona de forma nova e provocadora diante o apartheid: dá lugar ao discurso dos dominantes, cuja lógica não pode escapar à eficácia simbólica de um sistema de classificação. Nesse sentido, não lhe interessa exercer o papel de denunciante em nome dos direitos humanos, do antirracismo ou de algo parecido. Nas raras ocasiões em que Crapanzano "aparece" no texto é para expressar o seu incômodo em relação ao pensamento essencialista tanto dos seus interlocutores como dos seus colegas.

Em última instância, Crapanzano prefere se ocultar por detrás da multivocalidade, do dialogismo e da polifonia. Por isso, tal como aponta Mariza Peirano, na qualidade de antropólogo - isto é, como "autor" - opta pelo silêncio, "...talvez na expectativa de que, desta maneira, sua voz política soe mais alto" 25 . Esse tipo de abdicação é justificável sob o argumento de querer levar ao extremo uma experiência etnográfica em um contexto moralmente incômodo e, junto com essa tentativa, querer questionar também os próprios pressupostos "politicamente corretos" do senso comum antropológico. Apenas nessa arena a provocação de Crapanzano poderia ser válida, ainda que, no final do caminho, se revele ineficaz.

Evocarei, a seguir, uma visão do apartheid simetricamente oposta à de Vincent Crapanzano. Trata-se de uma versão veiculada, desta vez, não através do diálogo etnográfico, mas da violência incorporada na própria subjetividade de agentes concretos. Se Crapanzano é um ob-

${ }^{24}$ CRAPANZANO, Vincent. Waiting, op. cit. p. 20.

25 PEIRANO, Mariza, op. cit. p. 146. 
servador externo que, ao mesmo tempo, abdica da sua autoria para dar a palavra ao Outro, a versão que doravante apresentarei provém de um observador "participante": um porta-voz - um cronista - que mergulha, custe o que custar, na cena violenta do apartheid.

\section{O 'coração traidor' de Rian Malan}

Diferentemente de Vincent Crapanzano, Rian Malan não é um antropólogo profissional. É um cronista que registra, denuncia e interpreta a violência do apartheid. Em relação aos seus antepassados, Rian Malan é uma espécie de dissidente étnico, um traidor da "tribo branca" da África do Sul: os africâneres ou bôeres que Crapanzano entrevistou em sua etnografia. Nos primórdios da genealogia de Rian encontra-se Jackes Malan, um dos primeiros colonos brancos a chegar aos territórios da atual África do Sul. Jackes era um huguenote que foge das guerras religiosas da França de Luís XIV, passa pela Holanda e finalmente embarca rumo a Cidade do Cabo, onde a Companhia Holandesa das Índias Orientais possuia um dos seus postos mais importantes. Depois, chegariam outros Malan não menos ilustres: David Malan que, em 1788, escapou de uma região de fronteira e integrou a primeira rebelião africâner contra os ingleses. O topo dessa genealogia se completa, por assim dizer, com Daniel Malan (1874-1959), o Primeiro Ministro que chega ao governo em 1948 e implanta, na África do Sul, o regime do apartheid.

Como é possível ser um Malan e, ao mesmo tempo, ser contra o apartheid? Eis o paradoxo que atravessa a própria subjetividade de Rian Malan. Em outra ordem mais geral, a interrogação poderia ser reformulada nos seguintes termos: como fazer um esforço de alteridade e, então, questionar o sistema jurídico e repressivo construído pelos próprios antepassados, arquitetos do apartheid? A questão não poderia ser resolvida sem uma cota razoável de sofrimento, purgação e exílio. O assunto remete, mais uma vez, ao problema da "autori- 
dade etnográfica" ou, colocado em outros termos, ao papel crítico do autor, em uma sociedade que não admitia dissidências, contra as classificações racistas criadas por um Estado.

O primeiro exercício primordial para se enxergar de fora é a auto-ironia, e Rian Malan sabe praticá-la com requinte. Nesse registro de estratégias autobiográficas, Malan evoca as primeiras inquietudes antirracistas da juventude branca progressista. Os primeiros sintomas de politização dos jovens brancos incomodados com o apartheid incorporavam um ingrediente espontâneo e lúdico: “...Era jóia ser ligado em cultura negra”, diz Malan, “...de modo que passamos a adotá-la da mesma forma que adotamos calças de boca larga. $\mathrm{Na}$ Johanesburgo branca, "cultura negra" inclinava-se a significar James Brown e James Baldwin, não a cultura daquele velho sábio nas montanhas ou dos negros em nossos quintais..."26. O distante, pois, não ameaçava como o próximo. Contudo, um momento decisivo da sua experiência anti-apartheid é o ingresso no jornal The Star, em dos vespertinos mais importantes da África. The Star proporciona a Rian a possibilidade de ver de perto o funcionamento do país. Mas, sobretudo, essa experiência profissional the possibilita a oportunidade de sair a "campo".

Aos sul-africanos brancos que queriam militar a favor da causa negra se lhes apresentavam uma série de contradições. Contudo, a maioria militava no "cartismo", que se baseava em um documento, The Freedom Charter, do Congresso Nacional Africano. Tratava-se de um documento ambíguo, aberto a múltiplas interpretações que, dentre outras coisas, declarava que "....as portas do saber seriam abertas a todos, a terra dividida entre os que nela trabalhavam e a renda derivada da extração do ouro entre os que a mineravam". Os liberais, diz Malan, “...a consideravam uma ata liberal, os social-democratas acreditavam que ela refletia seu programa e os marxista-leninistas linhas- duras não viam nada no texto que pudesse contradizer seu

${ }^{26}$ MALAN, Rian. Coração Traidor, op. cit. p. 55. 
ponto de vista" 27 . No entanto, a participação política dos brancos que estavam contra o apartheid limitava-se a formas de intervenção meramente culturais. Essas manifestações eram "toleradas" pela polícia secreta do regime. Para Rian Malan, apesar das boas intenções, o papel dos brancos na luta anti-apartheid estava condenado por uma "lei de cumplicidade genética". Mesmo lutando com fervor contra um crime não cometido, a cumplicidade estava, literalmente, estampada na "pele". Para entender esse drama, convém evocar as próprias impressões de Malan a respeito de uma passeata organizada pela Frente Democrática Unida, cujo objetivo era levar uma carta a Mandela, ainda na prisão:

A parte negra da demonstração transformou-se numa sangrenta batalha de rua entre a polícia e manifestantes, mas a branca foi um triste espetáculo (...) A manifestação da tarde deu-se de acordo com o coreografado. Sacudimos os cartazes e os guardas olharam feio de outro lado da rua. Como nos recusamos a nos dispersar, fomos contemplados com algumas granadas de gás lacrimogêneo. Pouco depois estava tudo terminado. A esquerda branca lutara contra o apartheid e agora nos sentíamos livres para voltar para casa e esticar o pescoço na direção dos distritos à procura da fumaça que nunca conseguíamos ver. Todos odiávamos o apartheid, mas, quando o jogo começava, quando chegava a hora da verdade nos distritos e tinha início a matança, não havia brancos no lado negro das barricadas. Nunca. Jamais. ${ }^{28}$

No jornal The Star, Malan se ocupa dos casos policiais, confrontando-se diretamente com a violência mais desapiedada do apartheid. Trata-se de uma violência pouco 'mediatizada' que, muitas vezes, nem os jornais nem a televisão eram capazes de mostrar. Graças à função que desempenha, os arquivos de Rian Malan não cessam de crescer: crimes "comuns", vinganças, repressão de pro-

\footnotetext{
27 Ibid. p. 166.

28 Ibid., p. 170-171.
} 
testos, matanças, e assim por diante. Contudo, longe de acumular dados desconexos, Malan articula e integra a descrição da violência política com as consequências que ela mesma produz na subjetividade dos atores envolvidos. Se tivéssemos que exagerar no elogio, poderíamos concluir que esse esforço de integração condensa, na crônica de Malan, uma sensibilidade antropológica aprimorada. Essa perspectiva aparece, sobretudo, em dois momentos particulares do seu trabalho: quando relata a história, o julgamento e a morte de $\mathrm{Si}$ mon Mpungose, "o homem do martelo", e quando narra a revolta de mineiros de Randfontein liderada por Themba Ngwazi, por volta de 1986. São momentos em que Malan não se satisfaz com as primeiras evidências de uma descrição superficial. Malan é, por assim dizer, um geertziano ${ }^{29}$ avant la lettre. Por isso, nas suas descrições almeja ir além dos acontecimentos relatados pela imprensa, convertendo-se em uma espécie de etnógrafo espontâneo e em um cronista privilegiado da violência urbana em pleno apartheid. Sua sensibilidade autoriza a analogia antropólogo-jornalista traçada pelo antropólogo sueco Ulf Hannerz, em sua pesquisa sobre os correspondentes de guerra. Ambos, antropólogos e jornalistas, deslocam-se por itinerários pouco familiares e, muitas vezes, perigosos. Ao mesmo tempo, muitos correspondentes de guerra tem elaborado obras autobiográficas de cunho reflexivo análogas a certas etnografias reflexivistas escritas, sobretudo, a partir da década de 1980. "Se o antropólogo se ocupa do Outro, também de alguma maneira o faz o jornalista", afirma Hannerz, "E se alguma vez o antropólogo, quando está no campo de trabalho, exige que lhe considerem como um herói, também o faz o jornalista para onde quer que ele seja destinado" 30 . Nas páginas seguintes evocarei, justamente, algumas das narrativas de violência descritas pelo "herói-etnógrafo" Rian Malan.

29 Relativo a Clifford Geertz, promotor da chamada “descrição densa" em antropologia.

30 HANNERZ, Ulf. Problemas en la aldea global: el mundo según los corresponsales extranjeros. In: Hannerz, U. Conexiones transnacionales. Cultura, gente, lugares. Madrid: Ediciones Cátedra, 1998. p. 183. 
A condenação dos ancestrais ... e a violência do apartheid

O pequeno "ato" que evocaremos a seguir é representativo de um drama maior. Para compreender os seus significados, é necessário passar das descrições superficiais às descrições densas. Trata-se da história de Simon Mpungose, o homem que, com um martelo, aterrorizou a vizinhança branca de Johanesburgo durante anos. Para além da sua trajetória individual, são vários os atores envolvidos nesse drama. Onde começa exatamente essa história? Quando Simon, com doze anos, começa a trabalhar nas plantações de cana? No final da sua adolescência, quando o juiz o condena a sete anos de reclusão? Ou no início de 1980, quando começa a ser conhecido como "o homem do martelo", conforme as crônicas policiais da época? Uma resposta adequada requereria, no entanto, um retorno ao passado, muito anterior ao seu nascimento, em 1948.

A “maldição" de Simon começa quando seus avós, Musa e Sonamuzi, constituíram uma união incestuosa, ofendendo aos amaDlozi, ancestrais venerados pelos Zulus. Simon jamais conseguiria se libertar dessa condenação social. Para o juiz que o condenou à morte em 1985, esse passado pouco interessava. Pois, tal como nos relembra Rian Malan, para os tribunais Simon era apenas "mais um Kaffir delinquente". Quanto ao próprio Simon, como veremos, pouco importavam as decisões do juiz: seu destino de morte já estava pré-anunciado a partir do seu nascimento.

Os crimes de Simon aterrorizaram a vizinhança branca. $\mathrm{O}$ modus operandi era quase sempre o mesmo. O homem começava a circular ao redor da casa; observava desde fora os moradores; aguardava até meia-noite quando, finalmente, ingressava nos quartos e os matava. Esse é o ponto de partida da narrativa de Malan: os assassinatos cometidos por Simon. No entanto, à medida que Malan avança o relato, a tumultuada trajetória de Simon recobra inteligibilidade. $\mathrm{O}$ que começa como mais um caso policial acaba se transformando 
em uma das tantas "experiências" da violência engendradas pelo apartheid. A aparente incoerência dos atos e a extrema crueldade com que são cometidos provocam o terror na opinião pública. "Não há explicação para o inexplicável” reza, tautologicamente, o adágio. Aquilo que parece completamente ilógico torna-se dramaticamente coerente na subjetividade de Simon. Talvez, a história do "homem do martelo" não comece em nenhuma parte, em lugar nenhum. Ou, possivelmente, as experiências de torturas sofridas, quando jovem, no cárcere, tenham colocado em funcionamento um dispositivo fatal. Simon, relata Rian Malan, trabalhava na pedreira da prisão sob as armas e os chicotes dos guardas:

Durante o dia inteiro quebrava pedras com o martelo e pensava nas coisas que tinha visto.

- Eu gostava dos brancos, contou ele mais tarde, mas depois de algum tempo acabei descobrindo que tenho medo de uma pessoa branca. Também perdi meu amor por elas.

As pedras que Simon quebrava eram esbranquiçadas.

- A gente segura a pedra em uma das mãos e quebra ela com facilidade. Não demora muito e elas começam a ser a cabeça dos brancos ${ }^{31}$.

Como tantos outros "bantos", Simon sofre as injustiças do apartheid, os castigos no cárcere e a destruição, pelas mãos do seu patrão branco, do seu documento de "passe". Finalmente, é submetido a um julgamento em uma língua que não conhece. Mas isso não explica tudo. Há algo na experiência de Simon irredutível à experiência de qualquer outro africano negro: ele é rejeitado pela sua própria etnia, pelos seus próprios parentes zulu e - o que nenhum branco "progressista" consegue entender - é aterrorizado pela sombra sempre presente dos seus antepassados. Ameaçado pelo espírito dos seus ancestrais, Simon não tinha escolha. Bruce Gillmer, o psicólogo forense que o entrevista durante o processo do julgamento,

31 MALAN, Rian, Coração Traidor, op. cit. p. 200. 
não consegue desvendar o problema. Minimiza os supostos delírios místicos de Simon como "sobrevivências" de uma África do Sul que já não existiria. Essa "razão instrumental" veiculada pelo psicólogo incomoda a Malan:

Sendo um homem sensível, bondoso, progressista e racional, partiu da hipótese que os velhos deuses da África estavam mortos. Em toda a maciça literatura sobre o apartheid, praticamente não se encontra uma palavra que lance luz sobre o segredo de Simon. Quando se menciona os velhos deuses, é dentro do contexto de valores culturais perdidos ou coisa parecida. Essa é a posição civilizada, progressista, e Bruce Gillmer é um homem civilizado. Nunca lhe ocorreria perguntar como andava a situação entre Simon e suas sombras ou o que exatamente quisera dizer ao afirmar que nunca poderia ser como os outros ${ }^{32}$.

A partir desse momento, Daniel Malan faz um esforço interpretativo que relembra o método do "paradigma indiciário" formulado pelo historiador italiano Carlo Guinzburg. "Por que", interroga-se Malan, "Simon cai em prantos diante dos juízes, justamente no instante em que tenta dizer algo sobre seus antepassados?"

Os antepassados de Simon foram grandes guerreiros. Pertenciam a um clã nobre. A tragédia tem início quando uma das filhas do clã (Musa, avó de Simon) engravida. Primeira transgressão:os zulus proibiam o sexo pré-nupcial. Quem se atrevera a desonrar essa filha dileta? Foi, justamente, o seu próprio primo de primeiro grau. Segunda transgressão: os zulus consideram incestuosa a relação entre primos de primeiro grau já que eles são considerados quase como irmãos. A transgressão ofendeu aos "amaDlozi", os antepassados. Estes estão sempre presentes, são

32 Ibid., p. 223. 
...entidades que vivem na casa, ajudando, aconselhando ou punindo seus descendentes. Alguns antropólogos chamam-nos de sombras, em vez de espíritos ou deuses, porque todo homem tem uma sombra presa aos seus pés, (...) As sombras exigem obediência às leis e tradições da nação, e uma delas é que não se pode tomar como esposa uma mulher do próprio clã, ..." ${ }^{133}$

Neto de Musa, Simon nunca conseguiu se liberar daquele estigma. Por isso, nunca pôde tornar-se um "humano". A ruptura com o tabu o condenou a uma perpétua animalidade, da qual só podia ser libertado através da morte. Nenhum psicólogo, nenhum branco esclarecido estaria disposto a entender essa condenação. Nesse caso, o universalismo, aos olhos dos brancos politicamente progressistas, devia se sobrepor às diferenças culturais. Atribuir algum significado ou inteligibilidade a semelhante misticismo teria implicado permanecer preso da "farsa", conforme alertava um jornalista do New York Times "...montada pelos racistas brancos dominantes para enganar turistas estrangeiros, fazendo-os acreditar que 'esses negros são mesmo diferentes, em muito mais formas do que se imagina'..." ${ }^{34}$. Malan, veremos, não compactua com a simplificação modernizadora nem com o universalismo abstrato que essa advertência veicula.

Apesar da mídia "esclarecida", esses traços culturais tinham uma perenidade profunda, e eram parte de uma África do Sul que raramente aparecia nos jornais ou na televisão. Nesse cenário, Rian Malan precisa juntar as peças de um quebra-cabeças. Aquela estranha resposta de uma mulher zulu - "Simon nasceu errado" - deixa-o perturbado: "A explicação que se seguiu foi tão confusa que precisei recorrer inicialmente a livros de antropologia para entender e no final a Nxongo, na sua qualidade de guardião das crenças que eu imaginava mortas há muito tempo"35. Malan, como jornalista, vai

33 Ibid., p. 215.

${ }^{34}$ Apud. Malan, Coração Traidor, op. cit. p. 228.

35 Ibid., p. 210. 
em busca do saber antropológico. Sem cair no essencialismo - tão criticado por Crapanzano - traz ao seu universo de compreensão as forças simbólicas que ainda operam na África do Sul, procurando encontrar uma coerência e um sentido naquilo que, aparentemente, resulta arbitrário e caótico.

\section{Pomadas mágicas contra canhões africâneres}

Por volta de 1985, o apartheid tornou-se uma ameaça para os próprios "capitalistas liberais" da Johannesburg Consolidated Investiments, a grande companhia mineira, proprietária das minas de Randfontein. Nesse local ocorreram, justamente, uma série de revoltas marcantes. Os patrões, começaram a vislumbrar a necessidade de criar instâncias de negociação. Era preferível aceitar a organização dos sindicatos mineiros do que mergulhar no abismo da ameaça do "bolchevismo" que prairava na imaginação paranoica dos proprietários das minas.

Foi precisamente nesse contexto que surge o National Union of Mineworkers (NUM), o Sindicato Nacional de Trabalhadores das Minas. Foi ali onde Themba Ngwazi, um xhosa do estado de Transkei começou sua militância. Uma das suas primeiras missões foi recrutar adeptos entre os mineiros negros de Randfontein. Contudo, a campanha não teve um bom começo:

Um grande número de trabalhadores tinha apenas medo de se filiar ao sindicato e perder o emprego. Outros eram homens de regiões isoladas, incultos, sem conhecimento dos conceitos do sindicalismo e resistentes à noção de pagar mensalidade. Para complicar ainda mais a situação, uma significativa porcentagem dos trabalhadores de Randfontein Estates era da tribo shangaan [shanganas] de Moçambique, e eles tinham verdadeiro pavor de se envolver em encrencas e ser mandados de volta para o seu país, que estava assolado pela guerra e pela fome ${ }^{36}$.

36 Ibid., p. 246. 
Uma das principais reinvindicações exigida pelos mineiros de Randfontein gravitava em torno do injusto sistema de waya-waya, tal como era chamado pelos mineiros. No início, os trabalhadores migrantes contavam com a garantia de que logo após passar uma temporada com suas famílias, retornariam - na data indicada nos seus registros de serviço - aos seus postos de trabalho. Ocorreu que as minas começaram a se mecanizar e, portanto, a prescindir da força de trabalho africana. Assim, "Muitos trabalhadores recebiam o registro de serviço sem data de retorno. Seus chefes prometiam que eles seriam chamados quando fossem necessários, mas às vezes a convocação jamais chegava" ${ }^{37}$. Diante essa ausência de convocatória os mineiros africanos começavam a se interrogar "Por quê? Por quê?" ("waya-waya"). As demandas contra o "por quê-por quê" não tardaram em consumar uma estratégia de luta.

O conflito entre mineiros e patrões se iniciam de maneira confusa. Ao mesmo tempo se verificaram conflitos inter-tribais, o que dificultava enormemente uma luta sindicalista unificada. $\mathrm{Na}$ verdade, o próprio sindicato dificilmente podia atender as expectativas diversas de mineiros que pertenciam a vários grupos étnicos. Com o surgimento de uma fração dissidente liderada por Themba, o rompimento da pretensa unidade se consolida. A luta, portanto, assumirá formas singulares.

Um dos principais choques entre a fração dissidente, liderada por Themba, e as forças de segurança da mina acontecerá em janeiro de 1986. Cabe lembrar que essas forças de segurança estavam munidos com uma moderna tecnologia contra-insurgente, que incluía um imenso canhão de água para dispersar multidões, além de outras armas convencionais. Os fatos, contudo, assumem contornos inesperados: longe de inspirar medo, as armas provocam uma euforia desafiadora nos mineiros. $\mathrm{O}$ armamento pesado não intimida os trabalhadores africanos. Os chefes de seguridade da

37 Ibid., p. 246-247. 
mina não conseguem entender tamanha bravata. Em pouco tempo, descobre-se que os mineiros contavam com o apoio de poderosos feiticeiros (inyangas):

De acordo com o agente secreto, o plano dos dissidentes era derrubar as autoridades da mina e instalar Themba no trono de Piet Rademeyer e, com esse objetivo, eles estabeleceram uma taxa de 2 rands por homem, levantando um total de 1800 rands. Com essa soma nas mãos, mandaram um representante ao Transkei, território tribal dos xhosas e pondos, para consultar um famoso inyanga, ou feiticeiro. O inyanga forneceu várias latas de graxa de sapato cheias de um poderoso e tradicional preparado para ser usado em batalhas, denominado intsizi, feito de cinza de ervas e gordura animal. A pomada era preta e esfregada em pequenos cortes feitos no corpo (...) transformaria as balas dos brancos em água, garantiu o feiticeiro ${ }^{38}$.

A desilusão com os poderes do intsizi não tardou a chegar. Os mineiros, vítimas da repressão e ensanguentados, não conseguiam encontrar uma explicação para a ineficácia da pomada. A profecia falhara e as suspeitas recaíram sobre o feiticeiro. Qual tinha sido o erro? Para que a pomada fosse eficaz, respondeu o feiticeiro, era preciso aguardar 72 horas. Além disso, quem a usava não podia tomar banho nem praticar sexo durante esse período. Os seguidores de Themba deram, então, uma segunda chance à pomada do feiticeiro.

Dificilmente essas manobras de feitiçaria interessariam a imprensa internacional, mais preocupada, talvez, com as denúncias das injustiças do apartheid do que com o aspecto microssociológico e simbólico do enfrentamento. Aliás, as questões sobre feitiçaria eram temas que começavam a incomodar a alguns setores progressistas da sociedade. Inclusive, membros da elite negra sul-africana, como

38 Ibid., p. 257-258. O itálico é de minha autoria. A crença na ineficácia das balas - ou das armas, em geral - do colonizador, do "branco", ou do estrangeiro é um aspecto recorrente nos chamados movimentos messiânicos e milenaristas, amplamente estudados por antropólogos e historiadores. 
o médico Nthatho Motlana, eram favoráveis a uma cruzada antifeitiçaria: "Quando o vizinho Moçambique começou a internar curandeiros em campos de reeducação, Motlana expressou sua aprovação e vivia constantemente exigindo que as autoridades sul-africanas impusessem suas próprias leis antifeitiçaria"39 " Era uma campanha curiosa", acrescenta Malan, "e seu aspecto mais interessante era que o Dr. Motlana parecia estar perdendo"40.

Houve um novo comício dos mineiros seguidores de Themba. $\mathrm{O}$ dirigente pronunciou um inflamado discurso à multidão, denunciando a lentidão do NUM por não tomar medidas mais radicais. A reunião foi reprimida com gás lacrimogêneo. Mas os seguidores de Themba não se intimidaram: mais uma vez estavam "protegidos" pela pomada mágica. "A pomada é forte" gritavam, "matem os bôeres!". A revolta se inicia. Na sequência, conseguem sair de uma nuvem de gás lacrimogêneo e formam um "chifre de boi", estratégia de luta inspirada na guerra africana do século XIX. Apesar dos disparos efetuados pelos guardas, os seguidores de Themba não mostraram medo e, enfurecidos, arremeteram contra dois policiais brancos que acabaram mortos. Para os proprietários da mina, os manifestantes tinham ido longe demais. A repressão acionou uma força sem precedentes em manifestações desse tipo; helicópteros e caminhões com tropas armadas se somaram aos policiais. Ao amanhecer, a polícia tinha feito 371 prisioneiros; mais de 40 mineiros jaziam moribundos ou mortos no campo de batalha ${ }^{41}$.

Rian Malan não pretende moralizar com seu relato. Apenas se limita a apresentar os dados com um olhar singular e penetrante. $\mathrm{Na}$ qualidade de descendente dos africâneres, escreve a partir de um lugar incômodo. Da mesma maneira que Simon, Rian é um "destri-

39 Ibid., p. 232.

40 Idem.

41 Ibid., p. 264. 
balizado" mas desta vez branco. Esse estar "fora de lugar" o situa, paradoxalmente, em uma posição privilegiada a partir da qual constrói um relato crítico da sua própria sociedade. Essa narrativa é, também, o autorretrato de um desertor, de um "traidor". Através dessa espécie de autoimolação como africâner, Malan não está interessado em provocar a piedade do leitor, nem uma recíproca empatia: seu objetivo é, simplesmente, desafiar as imposições indentitárias do apartheid, bem como seus respectivos lugares comuns. A força da sua narrativa consiste em trazer a dimensão da experiência e do "vivido" sem cair no autocentramento ou no solipsismo. Seu compromisso é mostrar como os conflitos e a violência atuam sobre o corpo da sociedade e, ao mesmo tempo, sobre a própria subjetividade humana. Em ambos os casos, esse esforço opera com a consciência de que o corpo social e a subjetividade humana não são meros receptáculos passivos de uma "política" de Estado. Com uma sensibilidade ímpar, Malan percebe que a "razão instrumental" e a "razão simbólica" dificilmente podem agir separadamente. Para dizê-lo em outros termos - e as nossas aspas operam aqui como antídoto contra o relativismo ingênuo - Malan parece reconhecer que a força e a eficácia dos canhões africâneres e a "força" e a "eficácia" das pomadas xhosas são, na verdade, duas faces de uma mesma moeda.

\section{Palavras finais}

A etnografia plurivocal de Crapanzano ressalta a relação africâneres/ingleses. Em contraposição, no relato de Malan, a relação e o conflito primordial é entre brancos e negros. Crapanzano preocupa-se em introduzir as múltiplas vozes de seus entrevistados. Malan, ao contrário, coloca-se na cena na qualidade de intérprete e cronista, mas, sobretudo, como cidadão sul-africano. A "política" textualista de Crapanzano é desaparecer como autor; já Malan intervém no texto até a exaustão. Crapanzano, em nome da polifonia bakhtiniana, pre- 
fere evitar a tentação da teoria. Por isso, Mariza Peirano sugere que ele escolhe o silêncio teórico em prejuízo da análise, esquecendo-se que “...a ausência teórica é também uma posição teórica"42. Em Rian Malan, a análise é substituída por uma autoironia dessacralizadora: trata-se do testamento de um "traidor".

Malan, lembremos, escreve seu livro depois de um período de oito anos de exílio em Los Angeles. Sua crônica resulta das observações que registra após seu retorno ao seu país quando, em virtude do período de transição, a paisagem política havia mudado. Malan regressa transformado desse exílio, não conseguindo deixar de sentir um estranho mal-estar. As reformas políticas da segunda metade da década de 1980 eram aparentes, e o apartheid era tratado de forma suavizada. "Voltei para a África do Sul, mas, ali, a agonia do país", diz, "continuava sendo algo que eu lia nos jornais". Na África do Sul da transição havia lugar para os rituais politicamente corretos e para o exercício da boa consciência progressista dos brancos interessados, agora, em "cultura" negra. Malan retorna a África do Sul e "descobre" que "...as peças do teatro negro eram encenadas nos reluzentes panteões da cultura branca, diante de platéias encantadas, constituídas de liberais brancos usando smokings e jóias, que desembolsavam 10 dólares cada um para serem afogados em abominação e calúnia"43. Era a época da transição e do fim da censura.

Em 1990 foram iniciadas as primeiras negociações entre o presidente De Klerk e os membros do Congresso Nacional Africano (CNA). Nesse mesmo ano, o CNA anuncia a suspenção da luta armada. Como resposta a essa suspenção, De Klerk promete libetar os presos políticos e facilitar o retorno dos exilados. O fim do apartheid estava próximo. Uma série de reformas políticas são colocadas em prática. Após as primeiras eleições livres realizadas na África do

42 PEIRANO, Mariza G. S. O encontro etnográfico e o diálogo teórico, op. cit. p. 146.

43 MALAN, Rian. Coração Traidor. op. cit. p. 157. 
Sul, Nelson Mandela é aclamado presidente do país ${ }^{44}$. Vincent Crapanzano e Rian Malan - intérpretes contemporâneos do apartheid - retomavam seus respectivos postos de trabalho. Em 1994, ano que data o fim do apartheid, Crapanzano ensinava antropologia na CUNY (City University of New York) enquanto Rian Malan debutava como jornalista e documentarista da BBC.

Crapanzano e Malan nos fornecem dois relatos dissímeis. Os recursos estilísticos, as estratégias de escrita e a construção das narrativas transitam por caminhos opostos. Há, no entanto, coincidências incontornáveis. Ambos conseguem identificar de maneira bem sucedida um incômodo: o mal-estar do branco sul-africano que resiste a assumir como própria a criação desse engendro jurídico e político que foi o apartheid. Para dizê-lo com as palavras do escritor J. M. Coetzee, reproduzidas na epígrafe, tanto Crapanzano como Malan conseguem narrar o "ressentimento abrasador" (burning resentment) e a "raiva mordaz" (bristling anger) que atordoa a boa consciência do sul-africano branco. Trata-se de duas testemunhas que, por caminhos diferentes, buscam entender o peso psíquico suportado por um sujeito - ora individual, ora coletivo - que se recusa a assumir como próprios os crimes cometidos em seu nome.

Enviado em 20 de agosto de 2015

Aprovado em 30 de outubro de 2015

44 RIBEIRO, Fernando Rosa. Eleições Na África do Sul: Uma Visão de Primeira Mão. Estudos Afro-Asiáticos. Rio de Janeiro, vol. 26, p. 159-166, 1994. 